\title{
EOSINOPHILIC INFILTRATION OF THE STOMACH AND BOWEL
}

By I. M. OrR, M.D., Ch.M., F.R.C.S. Ed., A. A. Miller, M.D. and J. Y. W. Russell, F.R.C.S.Ed. Preston Royal Infirmary

Infiltration of various organs, notably the lung, has been recognized as an allergic manifestation since Loeffler (1932) first described his syndrome, the main features of which were:

I. Recurring mild afebrile illness with minimal physical signs.

2. Slight and transient infiltration of the lung fields noted on chest X-ray.

3. Variable and inconstant eosinophilia in the blood picture.

Kaijser (1937) reported a case in which the most significant findings were an infiltration causing thickening of the pyloric end of the stomach, eosinophilia in the blood picture and marked allergic sensitivity to onions.

Herrera and de la Guardia (1948) reported a similar case in which operation was undertaken for pyloric obstruction. Although no blood eosinophilia was noted before the operation it became a marked feature later. In the same year Barrie and Anderson described a case of a woman aged 27 who developed pyloric obstruction due to concentric hypertrophy of the muscular coats of the stomach, pylorus and duodenum with massive eosinophilic infiltration of the pylorus. The patient was allergic to certain foods and had a constant blood eosinophilia. Moloney (1949) reported a case of hypertrophy of the muscle coats of the pylorus with eosinophilic infiltration, but in this case there was no evidence of allergy. Vanek (1949) reported a series of six patients with thickening of the gastric submucosa due to eosinophilic infiltration, none of whom gave a history of allergy or of blood eosinophilia.

In some reported cases, obstruction developed only after years of gastro-intestinal upset, as in the case recorded by Spencer, Comfort and Dahlin (1950), when a man aged 40 complained of epigastric and lower abdominal cramps with diarrhoea and vomiting recurring over a period of years. Pyloric obstruction was finally diagnosed and at operation a thickening of stomach, duodenum and proximal jejunum was found: A resection was carried out and microscopical examination of the specimen revealed sheets of mature eosinophils lying between the muscle layers of the stomach and bowel. Eosinophilic infiltration of serous and submucosal layers was less marked. The only case recorded in the literature, so tar, of jejunal infiltration without involvement of the stomach was reported by Polayes and Krieger, 1950.

One of the most complete and recently recorded cases is that of a male patient aged 55, described by Ruzic, Dorsey, Huber and Armstrong (1952). This patient suffered from a pyrexial illness associated with asthma. He complained of lower abdominal tenderness and his blood picture revealed eosinophilia. A barium meal examination revealed a filling defect of the lesser curvature of the stomach. Chest X-rays showed apical thickening suggestive of tubercle but Koch's bacilli were never found. At operation the stomach wall was found thickened from cardia to pylorus. No other organs were involved. Inspection of the interior of the stomach revealed no lesion of the mucosa. Histologically the biopsy specimen showed a chronic inflammatory process around the vascular channels in the submucosa, muscularis and serosa. The inflammatory reaction was most marked in the serosal zone and consisted of perivascular infiltration of lymphocytes, macrophages, giant cells and a fairly large number of eosinophils.

We have had the opportunity of investigating two such cases by laparotomy, biopsy, blood examination and skin sensitivity tests. One of these is of special interest in that four abdominal explorations were carried out over a period of as many years. On each occasion the area of involvement differed and on the final exploration the condition was found to be completely quiescent.

\section{Case Reports}

Case I. Mrs. F.R. The patient, a strongly built active farmer's wife, first attended hospital in 1940 when she was 38 years of age. She complained of intermittent attacks of abdominal pain 
associated with vomiting. These had first begun when she was 30 but had tended to increase in severity. The attacks lasted for periods varying from a few days to a month or six weeks, with intervals of complete freedom of as long as a year. The pain tended to be colicky and was mainly central but at first it seemed to extend in girdle fashion. The vomiting was usually bilious in character.

She gave no history of asthma or other respiratory trouble or anything to suggest dysentery. During the second world war she worked in a munition factory, where she developed dermatitis with swelling of the face and epistaxis whenever she came in contact with powder and even walking through the powder room brought out an almost immediate rash with itching of the fingers. She was transferred from the T.N.T. section to the clothing section where she continued work for four years during which time she had no further attacks.

A breast biopsy (chronic mastitis) was carried out in 1947 and appendicectomy had been performed in 1942 .

Clinical examination revealed only slight epigastric tenderness. A barium meal revealed no significant abnormality in the stomach or duodenum or lower in the gut.

First Operation. As the patient's symptoms persisted, a laparotomy was carried out on January 12, 1949. At operation there was found to be considerable smooth uniform thickening around the pylorus and some $5-6 \mathrm{~cm}$. of this was resected with immediate gastro-duodenal anastomosis. There was no evidence of a peptic ulcer.

Pathology. The biopsy specimen was a wedge shaped portion of the duodenal wall measuring ro $\mathrm{mm}$. in thickness. Histologically it showed atrophy of the mucosa and great hypertrophy of the muscle layer which extended almost to the serosa. An unusual feature in the interstitial perivascular connective tissue of the muscularis was a massive inflammatory infiltration consisting of numerous eosinophil leucocytes and a smaller number of lymphocytes and plasma cells (Fig. I): the serosa showed a few eosinophils and lymphocytes. There were no organisms or parasites: the appearance suggested that this was part of a generalized process. Nine days after the operation there was no eosinophilia; but after seven months and a year, there were steep rises, the total values being 1,320 per cu.mm. and 2,660 per cu.mm. (normal=I00-300 eosinophils per cu.mm.).

Convalescence after this operation was smooth and the patient remained well with a good appetite and digestion until January, 1952, when she was readmitted as an emergency with a three day

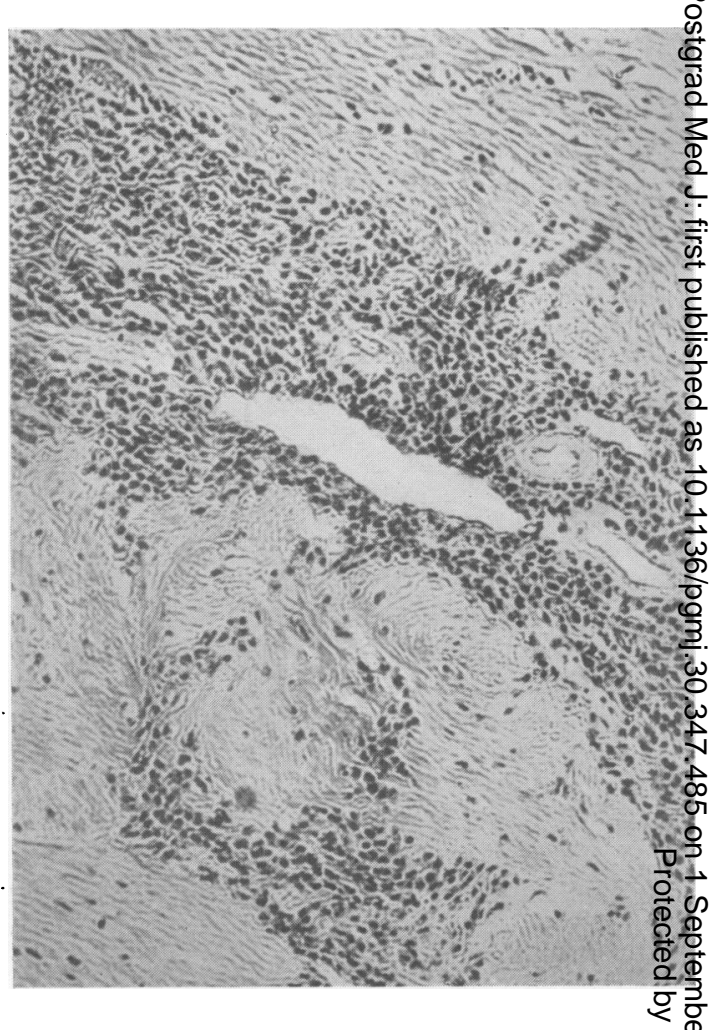

FIG. 1.-Section of the muscle layer of the duodegrm showing sheets of mature eosinophils in the imte stitial tissue and between muscle fibres.

H.E. $\times 250$.

history of right sub-costal pain associated wit弯 copious vomiting of green fluid.

On examination, acute local tenderness wa present under the right costal margin and provisional diagnosis of cholecystitis was made This was substantiated by a cholecystogram which showed non-filling of the gall bladder with dye No radio-opaque stones were seen.

Second Operation. At operation on January $2 \mathrm{G}$ 1952, the gall bladder was found to be adhere and the wall thickened. No calculi were present. Cholecystectomy was performed.

Pathology. The gall bladder which was norma in size contained dark green concentrated bile: there were no calculi and the mucosa was smoot throughout. Histologically it showed a min chronic inflammatory process in the submucosi muscularis and serosa: it was most marked in the submucosa and muscularis and consisted perivascular infiltration of lymphocytes, plasmat cells and a moderate number of eosinophile. Dilated and congested capillaries also containg many eosinophil granulocytes. In a few of the blood vessels they were as numerous as the ref 


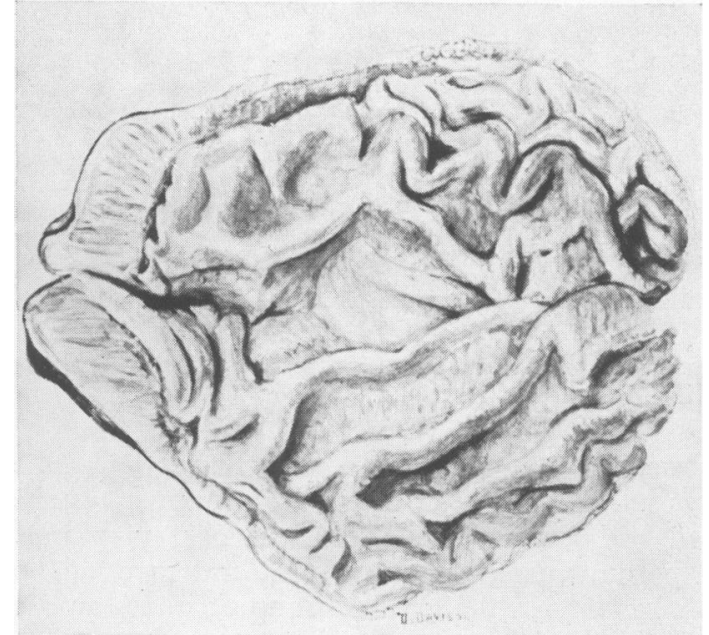

FIG. 2.-A drawing of a surgically removed segment of stomach and duodenum showing thickening of the gastric and duodenal walls and of the pylorus. The gastric mucosa appears normal. Natural size.

blood cells. Unfortunately there is no record of a blood picture for eosinophilia.

Convalescence was again uneventful and the patient returned home two weeks later.

She was readmitted to hospital in February, 1953, with recurrence of upper abdominal pain and vomiting which had been present for one week. In addition she had a good deal of backache. A tentative diagnosis of acute pancreatitis was made but the serum amylase was normal. Liver function tests were also normal. A barium meal was given but was inconclusive, the only abnormality being slight delay in gastric emptying.

Third Operation. At operation on February 28 , 1953, marked thickening of the pyloric region was again encountered and partial gastrectomy was decided upon. This was rendered difficult by the presence of numerous dense adhesions and shortening of the duodenum due to the previous pylorectomy. On bringing up the jejunum to perform the gastro-jejunal anastomosis it was found that the terminal part of the duodenum from a point just to the right of the superior mesenteric vessels downwards throughout the first $25 \mathrm{~cm}$. of the jejunum was greatly thickened and converted into a rigid tube with reddened congested walls almost like the typical appearances of acute regional ileitis (Crohn's disease). At the lower end of the thickened portion the gut gradually returned to normal. A small full thickness section of gut wall was taken for biopsy, the resultant defect being closed with difficulty as sutures tended to cut out so that finally an omental plug had to be used. The gastro-

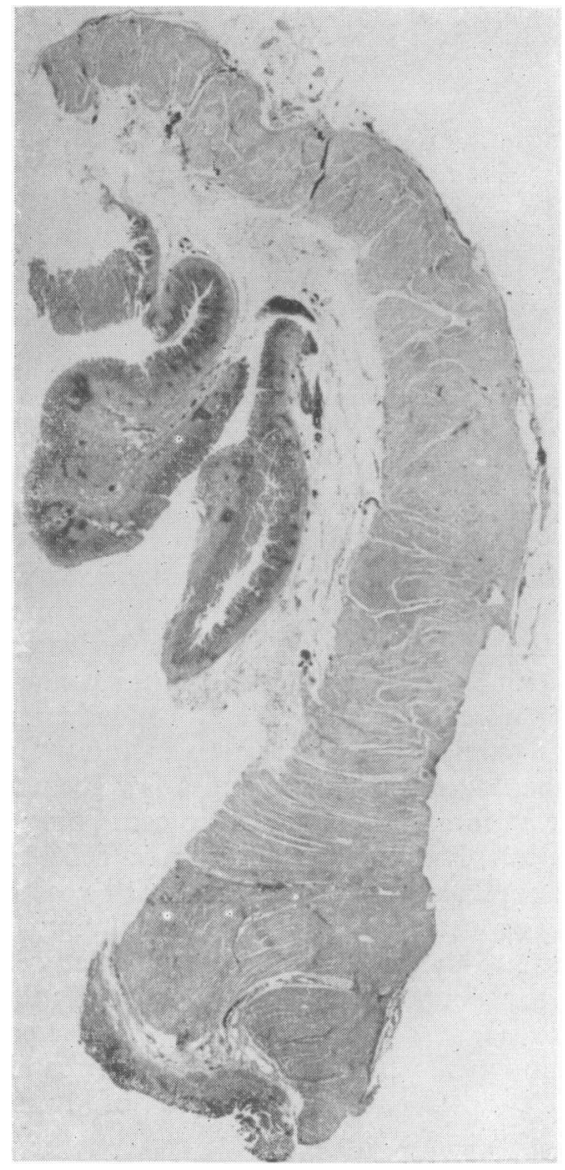

Fig. 3.-Section through the stomach, pylorus and duodenum showing marked thickening of the walls composed chiefly of the muscle layer. Stain H.E. $\times 6$.

jejunal anastomosis was then made using healthy jejunum well below the diseased portion.

Pathology. The resected portion of stomach consisted of the pyloric antrum, gastro-duodenal anastomosis and a fringe of the duodenal bulb, measuring along the greater curvature $13 \mathrm{~cm}$. On opening the specimen, the most important feature was considerable diffuse thickening of the walls, caused by concentric hypertrophy of the muscle layer which measured $12 \mathrm{~mm}$. at the ' pyloric' ring, the thickness decreasing gradually towards the upper level of the resection, about $8.5 \mathrm{~cm}$. from the 'pylorus' where it was $5 \mathrm{~mm}$. on the lesser and greater curvatures (Fig. 2). The gastric and duodenal mucosa was grossly normal, revealing no evidence of ulcer or neoplasm. The microscopical picture was essentially similar to that of the biopsy of the duodenum, the most remarkable feature being concentric 

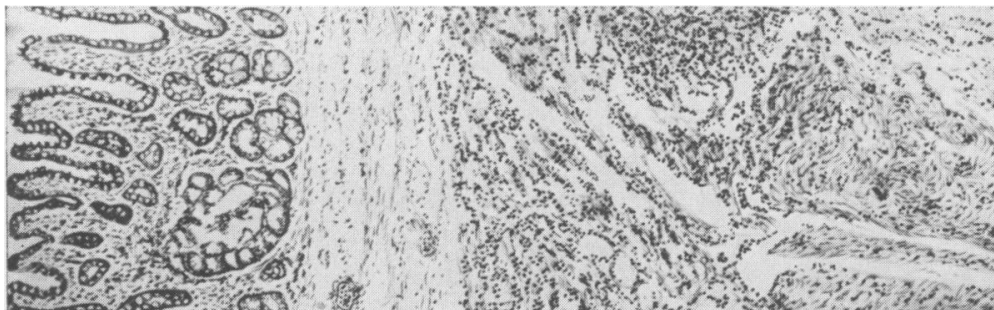

FIG. 4.-A drawing of low power microscopic fields of the thickened stomach wall from mucosa to serosa showi muscle hypertrophy with massive infiltration of eosinophils into the interstitial tissue.

thickening of the muscle fibres with marked diffuse cellular infiltration consisting predominantly of mature eosinophilic leucocytes in the perivascular connective tissue and between the muscle bundles. In some instances, the muscle bundles were split up and in others replaced by the massive eosinophilic exudate (Fig. 3). The mucosa and submucosa were not widened and the inflammatory reaction consisted of perivascular infiltration of lymphocytes, macrophages and a few eosinophils: the serosa formed a narrow strip containing many eosinophils, lymphocytes and plasma cells. Many of the capillaries were crowded with eosinophils suggesting eosinophilia in the circulating blood.

Four sub-pyloric lymph nodes showed reactive changes, predominantly sinus catarrh and follicular hyperplasia. Scanty eosinophilic infiltration was seen among the lymphocytes. In the capillaries of the capsules, the presence of numerous eosinophils was again noted.

The biopsy specimen of jejunal wall revealed an identical and equally severe condition. Again the outstanding feature was marked hypertrophy of the muscularis and a chronic inflammatory reaction with massive infiltration of mature eosinophilic leucocytes in the interstitial perivascular connective tissue (Fig. 4). The narrow strip of serosa was also packed with eosinophils. The mucosa was densely infiltrated with lymphocytes, plasma cells and a small number of eosinophils. The superficial portion of the submucosa was oedematous and relatively acellular, the deeper portion containing oesinophils which became progressively denser towards the muscle layer. Two months after the operation, examination of the peripheral blood again showed a normal value of 250 eosinophils per cu.mm.

Following this intervention the patient remained well for four months when she was again referred back to hospital with recurrence of upper abdominal pain and vomiting, this time associated with severe headache striking upwards from the neck towards the vertex. The patient's general condition was good and clinical examination was negative, and as she improved spontaneously she was allowed to return home a few days later. She was re-admitted after three days however, as she् had had a severe recurrence of her symptoms. A barium meal was carried out and revealed non abnormality in the gastric stump or in the upper. coils of the jejunum. As the pain and vomitir persisted a repeat laparotomy was suggested and readily agreed to by the patient. It was thought that resection of the terminal part of the duodenute and the upper jejunum would have to be carrieg out.

Fourth Operation. At operation on June $\overrightarrow{\sigma_{2}} \overrightarrow{\mathrm{f}_{\mathrm{f}}}$ I953, a moderate number of adhesions present around the jejunal loops, especially at site of the previous biopsy, and these were divided. The previously thickened duodenum and upper jejunum were found to have greatly improvedognd were now indistinguishable from normal. A si portion of jejunal wall was removed for biक्षिsy some $2 \mathrm{~cm}$. from the site of the previous biops The gastro-jejunal anastomosis was then inspecter and it was found to be free and mobile with suggestion of thickening or other abnormalite. The formation of an entero-anastomosis w@ considered, the suggestion being that the patien symptoms might be part of an 'afferent loọp syndrome '- the loop had originally to be left muç longer than usual, but as the gut wall was in the stage of recovery and showed no appreciabse dilatation, this procedure was not carried out and the abdomen was closed.

Pathology. Microscopically the jejunal biopsy showed an entirely different picture from the previous one. While the muscle hypertrophy was still the same, there was little worth-while evidenoe of the inflammatory reaction, only a few single and clumped eosinophils together with occasional lymphocytes and plasma cells being seen in the interstitial perivascular connective tissue. No eosinophils were seen in the capillaries. T condition would appear to have subsided. Four days after the operation however, the blood showed a raised eosinophil count of $I, 45^{2}$ per cu.mm.

During her convalescence and while still ફ̆ hospital, the patient had one bout of abdominal 
pain and vomiting but this was very short lived and she returned home two weeks after her operation. She has since remained well.

\section{Investigation of Allergic Sensitivity}

Although clinically well, the patient continued to show intermittent blood eosinophilia. On each of two occasions in September 1953, the blood picture revealed a slightly raised total eosinophil count of 544 per cu.mm. About the same time three specimens of faeces were examined for intestinal parasites with negative results.

In view of the history of T.N.T. dermatitis in I940, some of the T.N.T. powder was applied to the skin in the form of a patch test and the result was positive. The patient developed a blotchy erythema of the skin with vesiculation, and complained of nettle rash. In addition, there was a slight general reaction, with tiredness and spasms of abdominal pain. The blood eosinophil count was not raised.

The application of a complete range of allergens at the epidermal level showed in addition that the patient was sensitive to tree and flower pollens and to mixed moulds.

\section{Case No. 2}

Mrs. M. R. aged 42 years, was admitted to hospital on January 22, I949, complaining of severe colicky epigastric pain of three days duration. The colicky spasms occurred every three minutes and were associated with vomiting and diarrhoea. She passed seven motions on the morning of her admission to hospital.

Seven years previously she had a similar attack which had been diagnosed as acute gastritis. Another attack occurred three years later and lasted fourteen days.

She gave a history of allergic sensitivity to certain articles of food including chocolate. She ran a poultry farm but denied any sensitivity to feathers, to pollen or to bed making. She thought pastry, fruit cake and meat tended to upset her and precipitate her attacks. She never had an attack of urticaria. In her youth she had bronchitis which was never associated with asthma or with dust, feathers or grasses.

On abdominal examination she exhibited diffuse epigastric tenderness. No mass was palpable, there was no rigidity and no dilated bowel could be palpated. She was kept under observation for seven days and though the diarrhoea and acute pain settled down she remained tender in the epigastrum with a tendency to vomit. Her pulse and temperature remained normal throughout. A diagnosis of subacute cholecystitis was made and it was decided to explore the abdomen. Unfortunately no blood count was carried out prior to the operation.

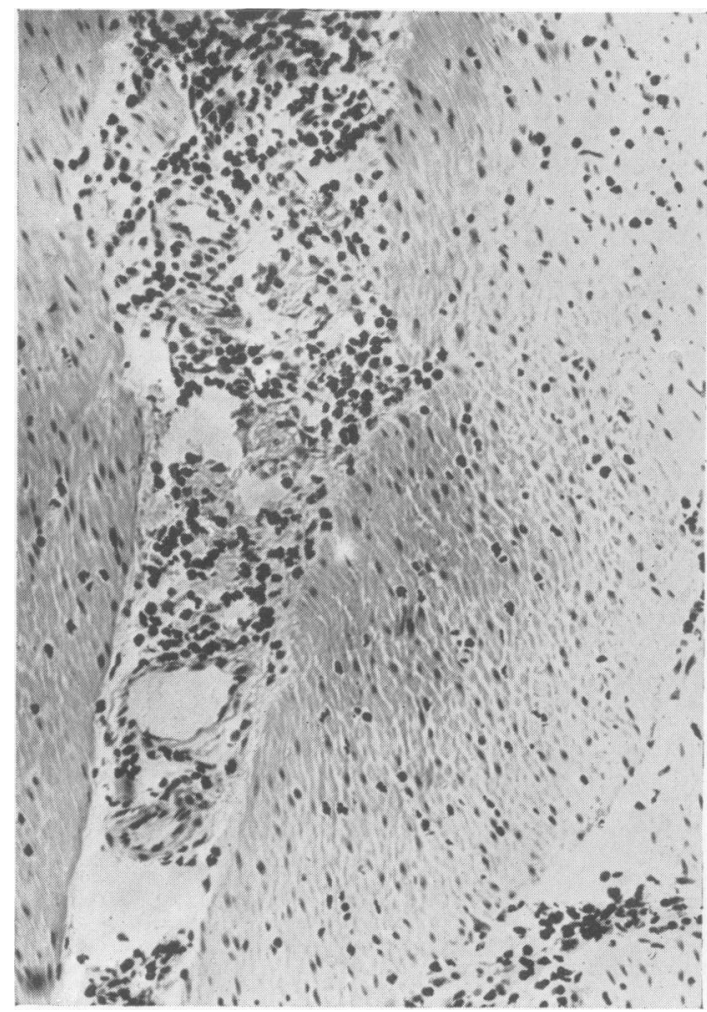

FIG. 5.-Section of the stomach wall showing muscle hypertrophy and eosinophilic infiltration in the periarterial connective tissue and between the muscle fibres. Stain H.E. $\times 25^{\circ}$.

Operation. On January 29, I949, the abdomen was opened with a right paramedian incision. The gall bladder was found to be healthy but there was marked thickening of the pylorus and pyloric antrum. No ulcer crater could be discovered. The thickening of the pylorus apparently caused some stenosis and a hemi-gastrectomy with a Bilroth I gastro-duodenal anastomosis was effected.

Pathology. The resected segment of stomach consisted of the pyloric antrum, the pylorus, and an incomplete cuff of the first part of the duodenum, which measured $2 \mathrm{~cm}$. There was no visible abnormality of the gastric or duodenal mucosa. About $2 \mathrm{~cm}$. of the pre-pyloric portion of the stomach, the pylorus and the first part of the duodenum were rigid due to diffuse thickening of their walls which measured ro $\mathrm{mm}$. in the prepyloric area and $15 \mathrm{~mm}$. at the pylorus (Fig. 5): beyond the pyloro-duodenal junction the thickening of the wall became progressively less marked until at the distal portion of the duodenum it measured only $5 \mathrm{~mm}$. The thickening was caused chiefly by concentric hypertrophy of the muscle layer which extended to the serosa. Histo- 


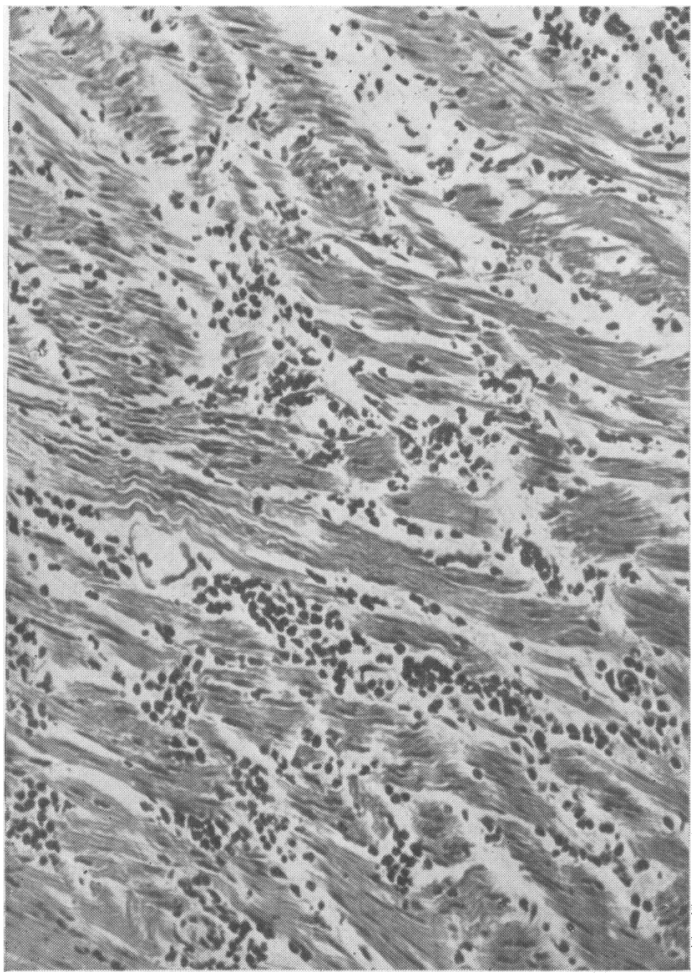

Fig. 6.-Section of the muscularis showing heavy infiltration of eosinophils between the muscle bundles. Stain H.E. $\times 25$.

logically the whole of the thickened portion of stomach, pylorus and duodenum showed great muscle hypertrophy with massive eosinophilic infiltration in the interstitial perivascular connective tissue and in thick lines and sheets of cells between the muscle layers (Figs. 6 and 7). Small numbers of macrophages were present among the eosinophils and an occasional small giant cell. In the mucosa and submucosa, the inflammatory reaction consisted of perivascular infiltration of lymphocytes, plasma cells, macrophages and a moderate number of eosinophils (Figs. 8, 9 and ro).

The patient made a smooth recovery from the operation and was discharged on February 15, 1949. After her return home she suffered from periodic attacks of diarrhoea and sickness, which lasted about two days, and recurred fortnightly. They ceased in three months, but the patient continued to complain of abdominal pain after eating pastry, meat and fruit cake. During a period of four years (1953) she remained well but had to be careful about her diet.

Investigation of Allergic Sensitivity

A blood examination on February 28, 1949, about a month after the operation showed a high

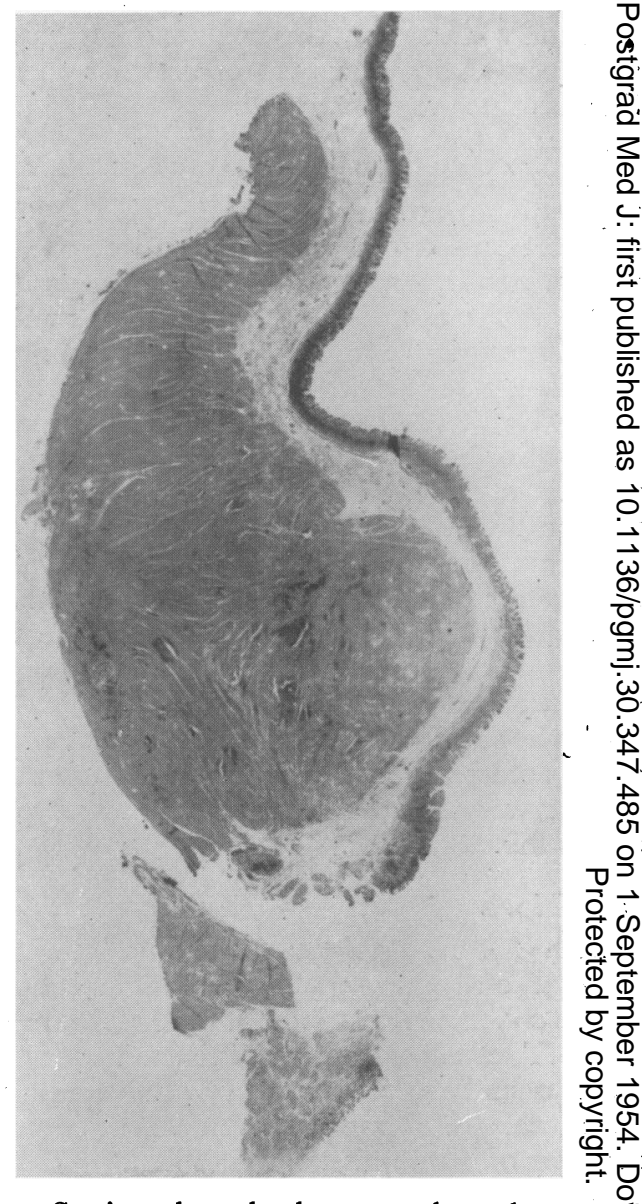

Fig. 7.-Section through the stomach, pylorus an duodenum showing marked thickening of the walls, composed chiefly of the muscularis proprim. Stain H.E. $\times 6$.

total eosinophil count of 1,170 per cu.mm. August and September of the same year after the periodic attacks of abdominal pain had ceased, the eosinophil counts were less raised, the figures being 500 per cu. mm. and 560 per cu.mm. Four years later in April and September, 1953, the eosinophil counts were still lower, the values being I 49 per cu.mm. and 62 per cu.mm.

Four specimens of faeces were negative for intestinal parasites.

The only substance to which the patient show an allergic reaction was chocolate. About half hour after being experimentally fed with chocolat she suffered severe continuous upper abdominad pain which gradually eased in about an hout Prior to the test the eosinophil granulocytes wefe 225 per cu.mm. and about one and a half hours later when the abdominal pain had become les severe they were not significantly raised, the valiee 


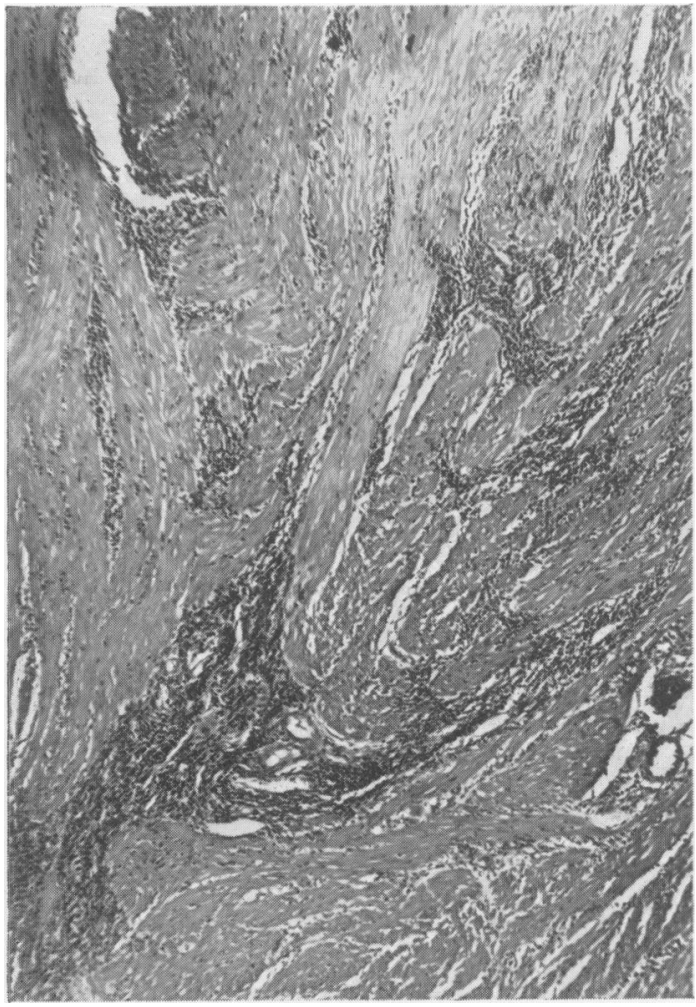

FIG. 8.-A section of the pylorus showing muscle hypertrophy and massive infiltration of eosinophils in the periarterial connective tissue and muscle fibres. Stain H.E. $\times 120$.

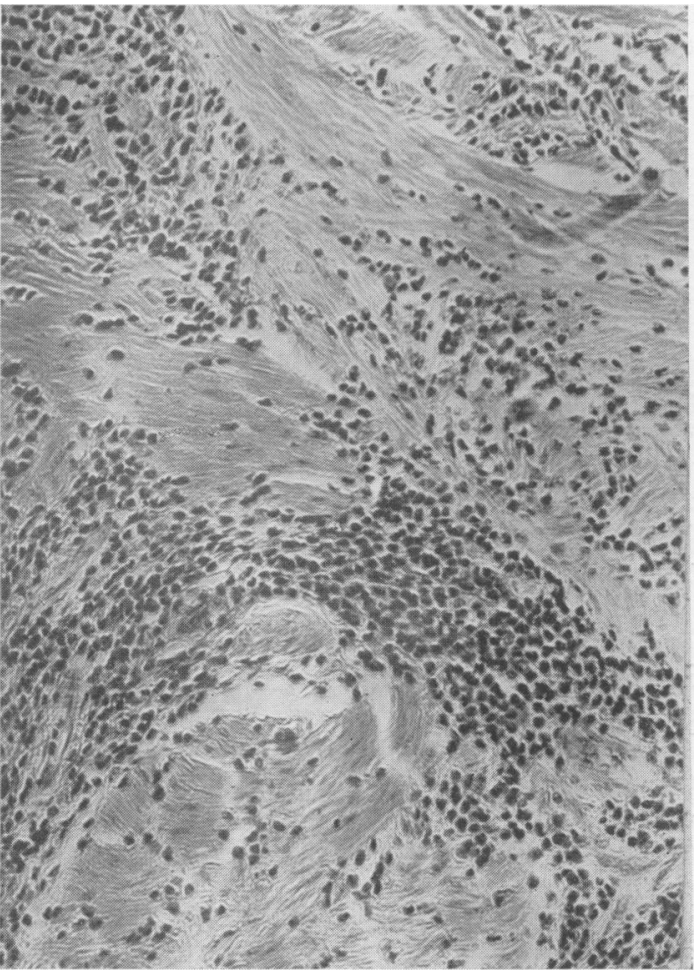

FIG. 9.-A high power field from the pylorus showing $\bigcirc$ massive infiltration of eosinophils in the connective $\overrightarrow{0}$ tissue and between the muscle fibres. Stain H.E. $\times 250$.

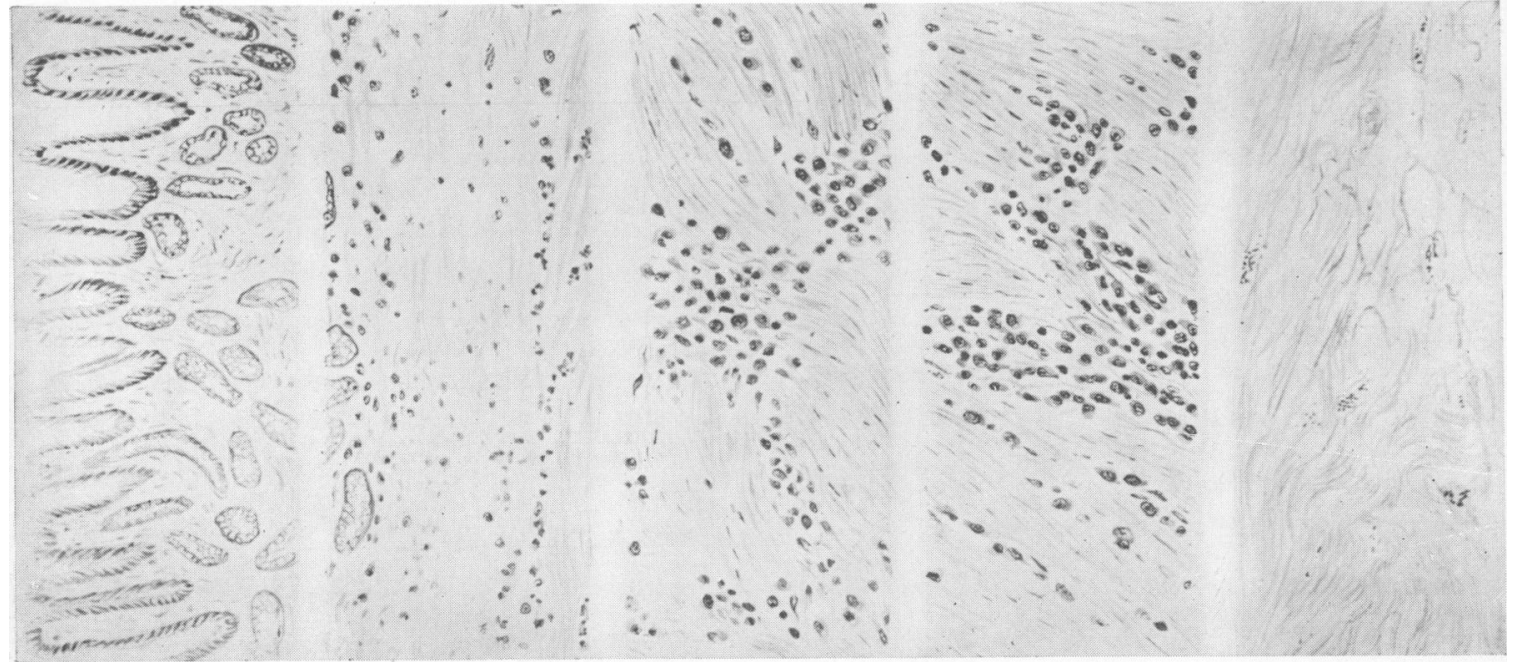

FIG. 10.-A drawing of high power fields from all the layers of the stomach wall showing cellular details. The muscularis is densely infiltrated by mature eosinophils while the mucosa and serosa show relatively few. 
being 262 per cu.mm. She gave a slight epidermal reaction to grass and tree pollens.

\section{Discussion}

The two cases here described, added to the six reported in the literature, suggest that there is a definite though rare clinical entity typified by a thickening of the pylorus, duodenum or jejunum, associated with eosinophilia. The condition in its fully developed form must be rare as one of us (A.A.M.) made histological examinations of 634 gastrectomy specimens with eosinophilic infiltration in mind, but has failed to find it except in the two cases described here. It is possible, however, that the condition does occur in milder forms and is not diagnosed as it appears to undergo spontaneous remission.

The concensus of opinion among those who have described cases of eosinophilic infiltration is that it is an allergic manifestation, though specific antigens have not been demonstrated in all cases. In one of our patients there was a marked association between work with T.N.T. powder and the onset of allergic symptoms. In the other patient the only allergic association appeared to be chocolate. It is of interest and perhaps significant that both patients were poultry farmers.

An interesting feature of the first case history is that on one occasion definite symptoms of cholecystitis appeared and on histological examination of the gall bladder eosinophilic infiltration was found. It may well be that the same infiltration might have been found in the liver or other organs had an investigation been made.

References appear in the literature to the variability and spontaneous remissions of the blood eosinophilia, but our first case demonstrates in a most convincing and dramatic manner that remission of the infiltration of the gastro-intestinal tract may take place. This patient underwent four laparotomies in the course of four years. The extent of the infiltration varied on each occasion, the last finding being a condition of complete remission.

It is unlikely that eosinophilic infiltration of the gastro-intestinal tract will be diagnosed in the absence of allergic phenomena unless symptoms indicate the need for a laparotomy. It is suggested, however, that a more frequent recourse to complete blood count might be made when investigating a patient with vague abdominal symptoms and a finding of eosinophilia should suggest the possibility of an allergic upset.

The treatment of eosinophilic infiltration should be conservative except in the presence of obstruction. In the milder case all that can profitably be done is to exclude possible allergic antigens in the anticipation of a spontaneous remission of the

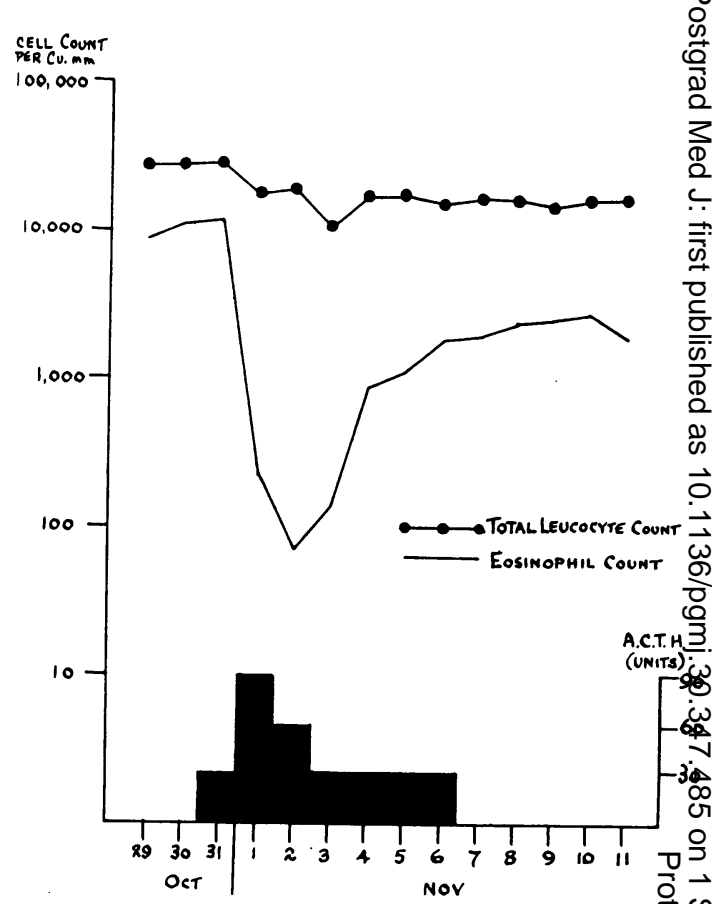

FIG. I I.-The initial response to A.C.T.H. was marded but on a reduced dosage and after withdrawail the drug a steady rise in the circulating eosinophis was noted.

condition. When there is evidence of obstructom a resection may be required, the extent of $\bar{q}$ h $\frac{1}{\mathrm{e}}$ tissue to be removed depending on the site of the infiltration. There does not appear to be ans justification for extensive resection as the conditio is not progressive as in Crohn's disease and vulnerable structures are involved a short circui would appear to be the most reasonable procedur

\section{Summary}

I. A review of the literature relating eosinophilic infiltration of the gastro-intestina tract is made.

2. Two cases of eosinophilic infiltration of the pylorus and duodenum are described.

3. It is suggested that the condition is a allergic manifestation, that it tends to undergo spontaneous remission and that more frequent use should be made of examination of the blood for eosinophilia when investigating vague abdomina symptoms.

\section{Acknowledgements}

Our thanks are due to Drs. C. K. Heffernan and C. C. Moir, for assistance in the laborato investigations. The photomicrographs and the graph are by Mr. F. Ramsden and the sections bo Mr. J. Wilkinson. 


\section{Addendum}

Since completion of this paper, one of the patients (J. R.) had a recurrence of symptoms almost identical to those during her previous attack. She was seen in her home and was found to have diffuse upper abdominal tenderness with a suggestion of an elongated thickening, possibly a loop of jejunum, in the left hypochondrium. As her symptoms did not subside with full sedation she was readmitted to hospital.

Blood examinations revealed a recurrence of eosinophilia with unusually high figures of 8,000 and 10,000 per cu.mm. on successive days with a peak rise to $I I, 600$ in a total white count of 27,300 per cu.mm.

As A.C.T.H. has been advocated in allergic conditions, it was decided to give her a short course. A dramatic fall in circulating eosinophils was produced with complete remission of symptoms (Fig. II). The drug was discontinued after six days and although the eosinophil count subsequently rose, the patient remained well and was allowed to return home.

\section{BIBLIOGRAPHY}

BARRIE, H. J and ANDERSON, J. C. (1948), Lancet, 855, 1007. BERGSTRAND, H. (1946), Ұ. Path. Bact., 58, 399.

HERRARA, J. M., and DE LA GUARDIA, J. (1948), Arch. Hosp. Santo Tomas, 3 , 10

KAIJSER, R. (1937), Arch. p. Klin. Chir., 188, 36

LOEFFLER, W. (1032), Beitr. Klin. Tuberk., 79, 368.

MOLONEY, G. E. (1949), Lancet, $1,412$.

POLAYES, S. H. and KRIEGER, J. L. (1950), Y.A.M.A., 143, 549 RUZIC, J. P., DORSEY, J. M., HUBER, H. L., and ARM. STRONG, S. H. (1952), F.A.M.A. 149, 535

SPENCER, J. R., COMFORT, M. Wै., and DAHLIN, D. C. VANEK, J. (1949), Am. F. Path., 25, 397.

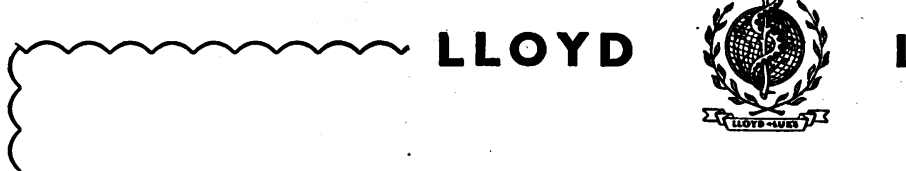

\section{LUKE}

FLOREY

LE QUESNE

WYLIE

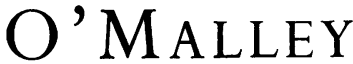

LECTURES ON GENERAL PATHOLOGY, edited by SIR Howard FloReY, M.D., F.R.C.P., F.R.S., Professor of Pathology, University of Oxford.

xiv +734 pp. 344 illustrations, 4 colour plates (1954) 63s. net

FLUID BALANCE IN SURGICAL PRACTICE, by L. P. LE QUESNE, B.M., B.Ch., F.R.C.S., Assistant Director, Department of Surgical Studies, Middlesex Hospital. viii +130 pp. 41 illustrations

(1954) 17s. 6d. net

PRACTICAL MANAGEMENT OF PAIN IN LABOUR, by W. D. WyLIE, M.B., M.R.C.P., F.F.A., Anaesthetist, St. Thomas's Hospital and the National Hospital for Nervous Diseases.

$x i i+148$ pp. 42 illustrations

(1953) 18s. 6d. net

MICHAEL SERVETUS, a translation of his geographical, medical and astrological writings, by Professor ChARLes D. O'MALLEY, Stanford University.

208 pp. 7 illustrations

(1953) 21s. net

\section{NEWMAN STREET, LONDON, W.}

Continued from page 475-Gabriel Richet, fean Crosnier and Georges Mathé

FUNCK-BRENTANO, J. L. (1953-4), 'Contribution a l'étude du mécanisme physiopathologique de l'anurie au cours de néphropathies aiguës.' Thèse, Paris.

HAMBURGER, J., CROSNIER, J. and MATHE, G. (I950), Bull. Soc. Med. Hop. Paris, 66, $170 \mathrm{x}$.

HAMBURGER, J. and MATHE, G. (1951), Pr. Med., 59, 265.

HAMBURGER, J, and MATHE, G. (I95 I), Pr. Med., 59, 265. Bull. Soc. Med. Hop. Paris, 66, 1716 .

HAMBURGER, J., MATHE, G. and CROSNIER, J. (1950b), Sem. Hop. Paris, 26, 3918 .

HAMBURGER, J. and MATHE, G. (1952), 'Métabolisme de l'eau' Paris, Flammarion.

HAMBURGER, J. and MATHE, G. (1954), 'Ciba Symposium, The Kidney.' London, Churchill.

HAMBURGER, J. and RIĆHET, G. (1952), Bull. et Mim. Soc. Med. des Hptx de Paris, 68, 368, 375.

HAMBURGER J., SERANE, J. and COURNOT, L. (195I), Sem. Hop. Paris, 27, 2289.

HARRIS, H., McDONALD, R. and WILLIAMS, W. (1952), Aust. F. exp. Biol., Med. Sci., 30, 33.
HARVEY, C., KNOWLES, J. and KAPLAN, S. A. (r953), Arch. intern. Med., 92, 189

KOLFF, W. J. (1947), New ways of treating uraemia. The artificial kidney, peritoneal lavages, intestinal lavage.' London, Churchill.

MERRILL, J. P. (1952) New Eng. F. Med., 246, 17.

MATHE, G. and CROSNIER, J. (1950), F. Urol. med. chir., 2 II6. MUIRHEAD, E. E., JONES, F. and GROLLMAN, A. (I952) F. Lab. clin. Med. JONES,
II. 505 . RICHET, G., ALAGILLE, D. and FOURNIER, E. (1954),

TANRET, P., BERNIER, J. J., LEGRAIN, $M$, and PIGNARD, $P$. (1952), $\mathrm{La}$ dialyse péritonéale. in Traitement des néphrites aiguës anuriques.' Masson, Paris.

TWISS, E. E. (1950), 'Treatment of uremia by dialysis and other methods with special regard to the principles and scope of intestinal dialysis.' M. Wytard, Rotterdam.

VALLERY-RADÓT, PASTEUR, MILLIEZ, P., LAROCHE, C LHERMITTE, 'F. and LEVAVASSEUR (1948), Bull. Soc. Med. Hop. Paris, 64, 908. 